\title{
THEORETICAL CALCULATION OF THERMODYNAMIC PROPERTIES AND DIFFUSION COEFFICIENTS FOR PURE ETHANOL, PURE WATER AND BINARY MIXTURE OF (ETHANOL + WATER) AS FUNCTION OF TEMPERATURE BY MOLECULAR DYNAMIC SIMULATION
}

\author{
NAHID SOHREVARDI ${ }^{a}$, FARHOUSH KIANI $^{\mathrm{a} *}$, FARDAD KOOHYAR ${ }^{\mathrm{b}, \mathrm{c} *}$
}

\begin{abstract}
In this research work, we presented the results of theoretical calculations for the change of thermodynamic properties such as enthalpy $\Delta H$, entropy $\Delta S$, heat capacity $\Delta C_{p}$, and Gibbs free energy $\Delta G$, for pure water, pure ethanol and interaction of mixture (50\% water $+50 \%$ ethanol) and binary mixture of (water + ethanol) under thermal equilibrium condition at $\mathrm{T}=(273.15,283.15,293.15,298.15,305.15,311.15,320.15,333.15) \mathrm{K}$ and at atmospheric pressure. This theoretical calculation was done using Molecular Dynamic (MD) simulation.

The results show that the values of $\Delta H$ and $\Delta S$ increase and also value of $\Delta C_{p}$ decreases by temperature growth. The obtained value of change of Gibbs free energy for interaction of mixture $(50 \%$ water $+50 \%$ ethanol) shows that this interaction is possible at $\mathrm{T}=(298.15,311.15,320.15$, 333.15) K. Also, it showed that the self-diffusion coefficient and the mutual diffusion coefficients increase by increasing temperature.
\end{abstract}

Key words: water, ethanol, mixture, interaction, thermodynamic properties, temperature, $M D$ simulation.

\footnotetext{
${ }^{a}$ Department of Chemistry, Faculty of Science, Ayatollah Amoli Branch, Islamic Azad University, Amol, Iran

b Division of Computational Physics, Institute for Computational Science, Ton Duc Thang University, Ho Chi Minh City, Vietnam

c Faculty of Applied Sciences, Ton Duc Thang University, Ho Chi Minh City, Vietnam

*Corresponding authors: fardadkoohyar@tdt.edu.vn; Farhoush_kiani@yahoo.com
} 


\section{INTRODUCTION}

Among various components that have been added to water, monohydric alcohols offer most favorable conditions for such studies owing to the amphiphilic nature of alcohol molecules. Alcohols strongly interact with water molecules through hydrogen bonds. The force of this interaction depends on the number and steric arrangement of their alkyl groups, also through hydrophobic effects. Some methods have been applied to the analyses of single atom materials [1], water [2-6] and more complex structured materials. Properties of ethanol, in liquid form, are usually experimentally known with high accuracy, and their calculation is most often straightforward. Heat capacity is a basic thermodynamic property, which could be used to characterize a liquid. It is directly linked with temperature derivatives of other basic thermodynamic functions and is therefore indispensable for calculation of differences in these functions between different temperatures. This invaluable information is widely used in physics and chemistry for establishing energy balances in thermodynamics for obtaining entropy and enthalpy values, and for calculating changes in interaction enthalpies with temperature. Since the knowledge of the heat capacities is also required for evaluating the effect of temperature on phase and interaction equilibria, variations in heat capacities serve as a sensitive indicator of phase transitions and are an important tool for understanding changes in the structure of liquid solutions [7].

Although, in principle, more observables could be computed this set includes the most important thermodynamic properties of the liquids, including temperature derivatives of energy and volume. In this work, the thermodynamic properties of the pure ethanol, pure water, ethanol/ water mixture, and ethanol/water interaction were calculated in the thermal equilibrium state as well as the temperature dependence of these properties are studied. Also, we will present the details of simulations. The obtained results and their meaning are discussed in subsequent sections.

\section{MOLECULAR DYNAMICS SIMULATION}

In this research work, Molecular Dynamics Simulations were performed using the GROMACS (version 4.5.4) [8-10] at various temperatures $(T=273.15,283.15,293.15,298.15,305.15,311.15,320.15,333.15 \mathrm{~K})$ and the constant atmospheric pressure. We have prepared different boxes at various temperatures to do these calculations. One box contains pure water and the other box contains pure ethanol at various temperatures. Also, the binary system of (water + ethanol) prepared with the ethanol mole fractions 
$x_{\text {ethanol }}=0.5$ at various temperatures. number of total molecules is 1000 in the each simulation. In the first step, we assessed the quality of molecules topologies produced automatically through the server PRODRG $[11,12]$ under the grooms 43a1 force fields [13]. SPC water model were used to describe the interactions of water [14]. Temperature (v-rescale) and pressure (Parrinello-Rahman) were controlled by using weak coupling thermostats $[15,16]$. Electrostatic interactions were treated by means of Particle Mesh Ewald (PME) approach $[17,18]$. Initial atomic velocities were created on the basis of Maxwellian distribution at the absolute temperature $[19,20]$. Numerical integrations were calculated by the velocity verlet algorithm [21]. In the next step, the prepared mixtures, at various temperatures, were put into the $6.5 \mathrm{~nm} \times 6.5 \mathrm{~nm} \times 6.5 \mathrm{~nm}$ cubic boxes. A steepestdescent algorithm was used to minimize the energy of each system with a cut-off distance for the short-range neighbor list $(1 \mathrm{~nm})$. In the last step, each system was simulated with a time step of $2 f s$ for the total time 50 ns. To maintain number of molecules and also values of pressure and temperature (NPT ensemble) during simulation [22], the coupling time intervals was set at $0.1 \mathrm{ps}$ and 2.0 ps for temperature and pressure, respectively. The compressibility was set at $4.5 \times 10^{-5} \mathrm{bar}^{-1}$ and it were used for a total time calculation. Also, the periodic boundary condition and integration of motion equations were carried out by the leap-frog algorithm [23] with a time step of 2 fs. LINCS algorithm [24] was used to fix the chemical bonds between the atoms. Coordinates were saved every 2 ps for subsequent analyses. Using a function called g_energy [25], we extract the enthalpy, $H$. The obtained results are finally shown in graphs and tables.

\section{RESULT AND DISCUSSIONS}

In this study, the values of change of enthalpy, $\Delta H$, change of entropy, $\Delta S$, change of heat capacity, $\Delta C_{p}$, and change of Gibbs free energy, $\Delta G$, for pure water, pure ethanol, water/ethanol mixture, and interaction of mixture ( $50 \%$ water $+50 \%$ ethanol) under thermal equilibrium condition at temperature range $\mathrm{T}=273.15 \mathrm{~K}$ to $\mathrm{T}=333.15 \mathrm{~K}$ and at atmospheric pressure were calculated using MD simulation. In these thermodynamic properties, the initial stage is $\mathrm{T}=273.15 \mathrm{~K}$ (the reference temperature) and the final stages are higher temperatures. Thermodynamic properties of solution have many applications in research works and industries [26].

For a thermodynamic system, the enthalpy can be defined as the below:

$$
\mathrm{H}=\mathrm{U}+\mathrm{PV}
$$


In equation $1, \mathrm{H}$ is enthalpy, $\mathrm{U}$ is internal energy, $\mathrm{P}$ is the pressure, and $V$ is volume of this system. At constant pressure, change of enthalpy can be obtained from below equation:

$$
\Delta H=\Delta U+P \Delta V
$$

In this theoretical study, all studied systems are closed. In a closed system, at constant pressure, the values of volume and $\Delta$ Vas well as internal energy and $\Delta U$ increase as temperature increases. It shows that according to equation 2 , in a closed system, the values of $\Delta \mathrm{H}$ increase with temperature growth. It is well know that in closed systems, $\Delta \mathrm{V}$ and $\Delta \mathrm{U}$ have positive values.

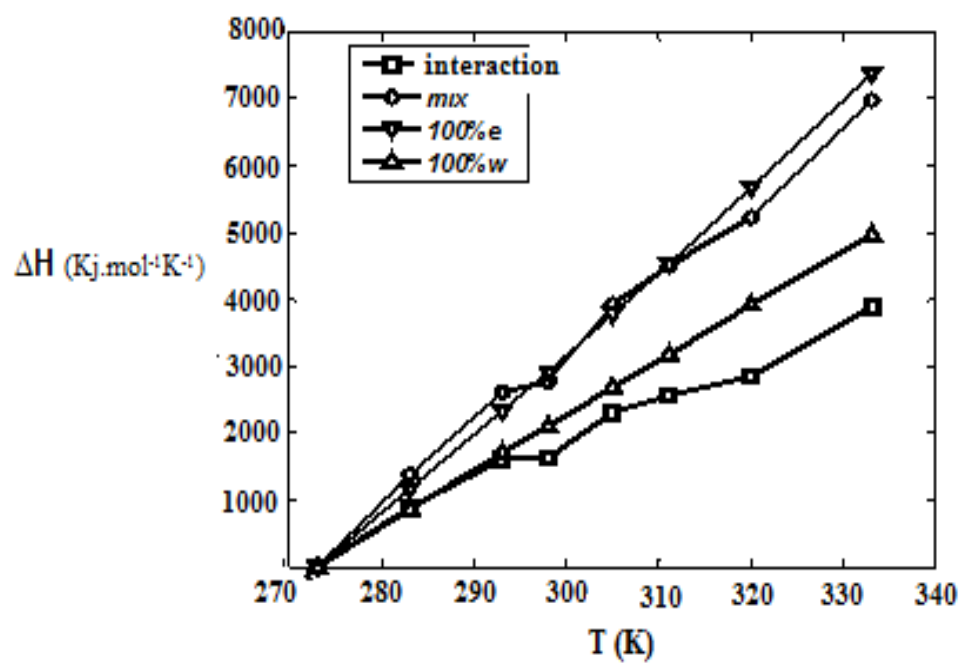

Figure 1. The change of enthalpy for interaction of mixture ( $50 \%$ water $+50 \%$ ethanol), water/ethanol mixture, pure ethanol, and the pure water as a function of temperature.

For our studied systems, the obtained values of $\Delta \mathrm{H}$ (at various temperatures) have been plotted in Figure 1. This figure shows that $\Delta \mathrm{H}$ for water/ethanol mixture, interaction of mixture $(50 \%$ water $+50 \%$ ethanol), pure ethanol and pure water increases by temperature increasing. In addition, the lowest value of $\Delta \mathrm{H}$ belongs to interaction of mixture (50\% water $+50 \%$ ethanol) and also, the highest values of $\Delta \mathrm{H}$ belong to mixture (ethanol + water) at $\mathrm{T}=(270-295) \mathrm{K}$ and pure ethanol at $\mathrm{T}=(310-340) \mathrm{K}$. 
The values of $\Delta \mathrm{H}$ for systems of this study can be fitted by the following equation:

$$
\Delta H=a_{\circ}+a_{1} T+a_{2} T^{2}+a_{3} T^{3}
$$

For studied systems of this work, the values of $a_{0}, a_{1}, a_{2}$, and $a_{3}$ has been shown in Table 1.

Table 1. The values of $a_{0}, a_{1}, a_{2}$, and $a_{3}$ (according to equation 3 ) for different systems of this study.

\begin{tabular}{ccccc}
\hline Systems & $\mathbf{a}_{\mathbf{0}}$ & $\mathbf{a}_{\mathbf{1}}$ & $\mathbf{a}_{\mathbf{2}}$ & $\mathbf{a}_{\mathbf{3}}$ \\
\hline interaction & -6379 & -85.7 & 0.6371 & -0.0008657 \\
water/ethanol mixture & -6379 & -153.5 & 0.9623 & -0.001147 \\
pure ethanol & -6379 & -95.31 & 0.5463 & -0.0004092 \\
pure water & -6379 & -87.42 & 0.5918 & -0.0006816 \\
\hline
\end{tabular}

The change of specific heat capacity or specific heat $\left(\Delta \mathrm{C}_{\mathrm{p}}\right)$ is obtained by the following equation:

$$
\Delta C_{p}=\left(\frac{d \Delta H}{d T}\right)_{p}
$$

We can obtain equation 5 by considering equations 3 and 4 :

$$
\Delta C_{p}=a_{1}+2 a_{2} T+3 a_{3} T^{2}
$$

Equation 5 can be used to calculate values of change of specific heat for studied systems of this work. Obtained data are listed in Table 2.

As it can be seen in Table 2 and Figure 2, the maximum and minimum values of $\Delta C_{p}$ belong to pure ethanol and interaction of mixture (50\% water $+50 \%$ ethanol), respectively. As we know, the specific heat capacity or specific heat $\left(C_{p}\right)$ is the amount of heat (usually in calories, kilocalories, or joules) needed to increase the temperature of a system by one degree (usually in Celsius or Kelvin). Among studied systems of this research work, pure ethanol has stronger intermolecular force. Therefore, there is need more amount of head to raise the temperature of this system by one degree. 
Table 2. The values of change of specific heat(according to equation 5) for different systems of this study at various temperatures

$$
(T=273.15 \mathrm{~K} \text { to } 333.15 \mathrm{~K}) \text {. }
$$

\begin{tabular}{|c|c|c|c|c|c|c|}
\hline \multicolumn{7}{|c|}{$\Delta \mathrm{C}_{\mathrm{p}}\left(\mathrm{Kj} \cdot \mathrm{mol}^{-1} \cdot \mathrm{K}^{-1}\right)$} \\
\hline $273.15 \mathrm{~K}$ & $283.15 \mathrm{~K}$ & $293.15 \mathrm{~K}$ & $298.15 \mathrm{~K}$ & $305.15 \mathrm{~K}$ & $311.15 \mathrm{~K} 320.15 \mathrm{~K}$ & $333.15 \mathrm{~K}$ \\
\hline \multicolumn{7}{|c|}{ interaction of mixture ( $50 \%$ water $+50 \%$ ethanol) } \\
\hline 68.5757 & 66.87004 & 64.64495 & 63.33762 & 61.28921 & 59.3308556 .04271 & 50.5504 \\
\hline \multicolumn{7}{|c|}{ water/ethanol mixture } \\
\hline 115.4683 & 115.572 & 114.9875 & 114.4372 & 113.3777 & 112.2012109 .9719 & 105.7676 \\
\hline \multicolumn{7}{|c|}{ pure ethanol } \\
\hline 111.5413 & 115.6382 & 119.4895 & 121.3231 & 123.787 & 125.8032128 .6618 & 132.4397 \\
\hline \multicolumn{7}{|c|}{ pure water } \\
\hline 83.31593 & 83.7767 & 83.82852 & 83.70107 & 83.35087 & 82.8912181 .92567 & 79.94619 \\
\hline
\end{tabular}

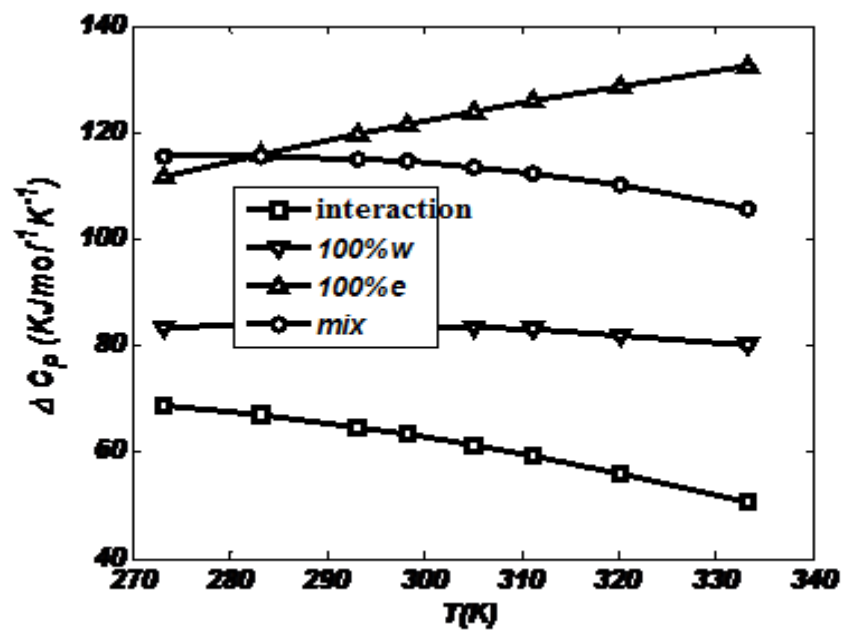

Figure 2. Changes of specific heat for interaction of mixture ( $50 \%$ water $+50 \%$ ethanol), water/ethanol mixture, pure ethanol and pure water as a function of temperature.

Figure 2 shows the changes of specific heat for studied systems of this work at different temperatures. In this figure it is obvious that the values of $\Delta \mathrm{C}_{\mathrm{p}}$ for interaction of mixture (50\% water $+50 \%$ ethanol) and water/ethanol mixture decrease by temperature growth. Also, the value of $\Delta \mathrm{C}_{\mathrm{p}}$ for pure ethanol increases by temperature increasing. 

follows:

Entropy change $(\Delta S)$ for our studied systems can be calculated as

$$
\Delta S=\int_{273.15}^{333.15} n C_{p} \frac{d T}{T}
$$

For studied systems of this work, the obtained values of $\Delta S$ have been plotted in Figure 3 at different temperatures.

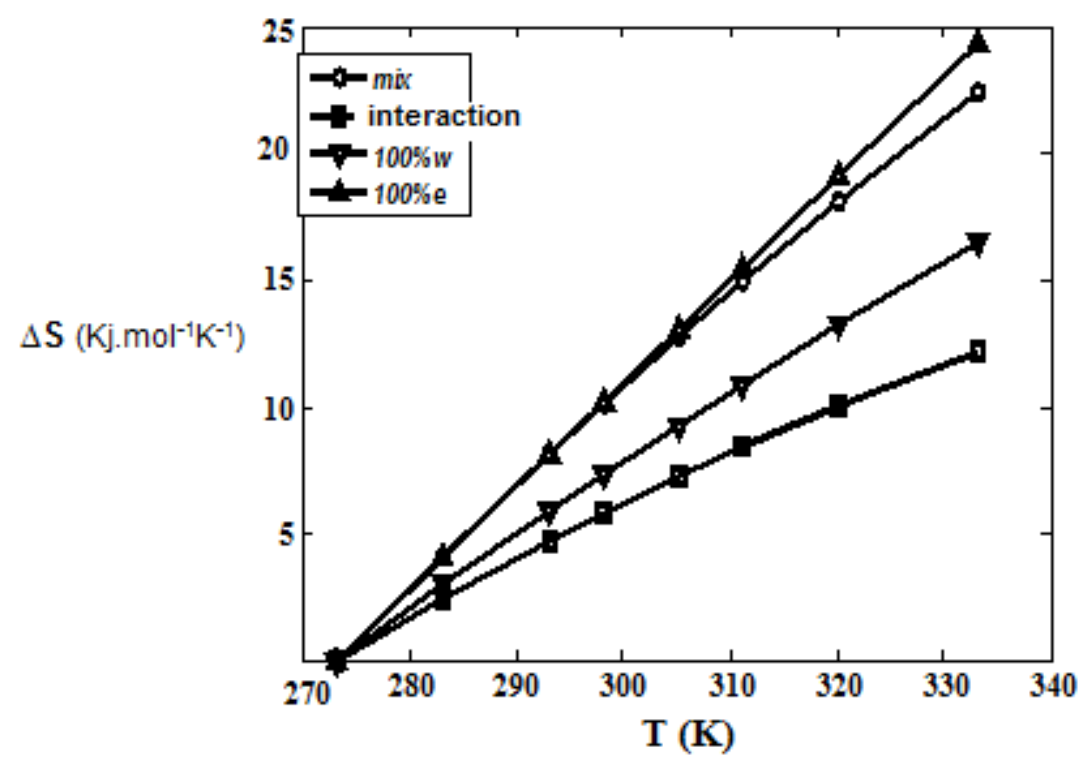

Figure 3. The entropy changes for interaction of mixture $(50 \%$ water $+50 \%$ ethanol), water/ethanol mixture, pure ethanol, and pure water as a function of temperature.

As it can be seen in Figure 3, the values of $\Delta S$ for our studied systems obey from below order:

$$
\Delta S_{\text {(pure ethanol) }}>\Delta S_{\text {(waterlethanol mixture) }}>\Delta S_{(\text {water) }}>\Delta S_{\text {(interaction) }}
$$

The change of Gibbs free energy $(\Delta G)$ can be calculated by the following equation:

$$
\Delta \mathrm{G}=\Delta \mathrm{H}-\mathrm{T} \Delta \mathrm{S}
$$


Using Equation 8, for studied systems of this work, the values of $\Delta G$ were calculated and listed in Table 3. It is clear that interactions are possible which their values of $\Delta G$ are negative. As it can be seen in Table 3 , for interaction of mixture (50\% water $+50 \%$ ethanol) in this study, the value of $\Delta \mathrm{G}$ are negative at $298.15 \mathrm{~K}, 311.15 \mathrm{~K}, 320.15 \mathrm{~K}$, and $333.15 \mathrm{~K}$. Therefore, this interaction will be possible only at $298.15 \mathrm{~K}, 311.15 \mathrm{~K}, 320.15 \mathrm{~K}$, and $333.15 \mathrm{~K}$.

Table 3. The values of change of Gibbs free energies for water/ethanol mixture, interaction of mixture (50\% water $+50 \%$ ethanol), pure ethanol, and pure water at different temperatures ( $T=273.15 \mathrm{~K}$ to $333.15 \mathrm{~K})$.

\begin{tabular}{|c|c|c|c|c|c|c|c|}
\hline \multicolumn{8}{|c|}{$\Delta \mathrm{G}\left(\mathrm{Kj} \cdot \mathrm{mol}^{-1} \cdot \mathrm{K}^{-1}\right)$} \\
\hline $273.15 \mathrm{~K}$ & K $283.15 \mathrm{~K}$ & $293.15 \mathrm{~K}$ & $298.15 \mathrm{~K}$ & $305.15 \mathrm{~K}$ & $311.15 \mathrm{~K}$ & $320.15 \mathrm{~K}$ & $333.15 \mathrm{~K}$ \\
\hline \multicolumn{8}{|c|}{ water/ethanol mixture } \\
\hline 0 & 186.313 & 221.247 & -236.046 & 26.612 & -156.849 & -567.664 & -489.658 \\
\hline \multicolumn{8}{|c|}{ interaction of mixture ( $50 \%$ water $+50 \%$ ethanol) } \\
\hline 0 & 175.970 & 227.397 & -106.624 & 89.993 & -53.814 & -388.734 & -176.397 \\
\hline \multicolumn{8}{|c|}{ pure ethanol } \\
\hline 0 & -8.626 & -72.928 & -1140.167 & -206.325 & -292.195 & -450.177 & -742.278 \\
\hline \multicolumn{8}{|c|}{ pure water } \\
\hline 0 & -3.979 & -49.352 & -84.635 & -146.406 & -210.192 & -320.478 & -503.548 \\
\hline
\end{tabular}

Figure 4 displays self-diffusion coefficients (D)for pure ethanol, pure water and mixture as a function of temperature. Figure 5 shows the mutual diffusion coefficients ( $D_{\text {ew }}$ ) for mixture (water + ethanol) at various temperatures. Figure 4 shows that by increasing temperature, the self-diffusion coefficient increases. In addition, self-diffusion coefficient for the pure water and waterethanol mixture are maximum and minimum, respectively. The force of bond between atoms in water-ethanol mixture is stronger than that of in the pure ethanol and pure water. All these explanations show that the value of selfdiffusion coefficients has inverse relationship with the force of bond between atoms in a mixture.

On the other hand, Figure 5 shows that for mixture (water + ethanol), the values of mutual diffusion coefficients $\left(D_{\text {ew }}\right)$ increase by temperature growth. 


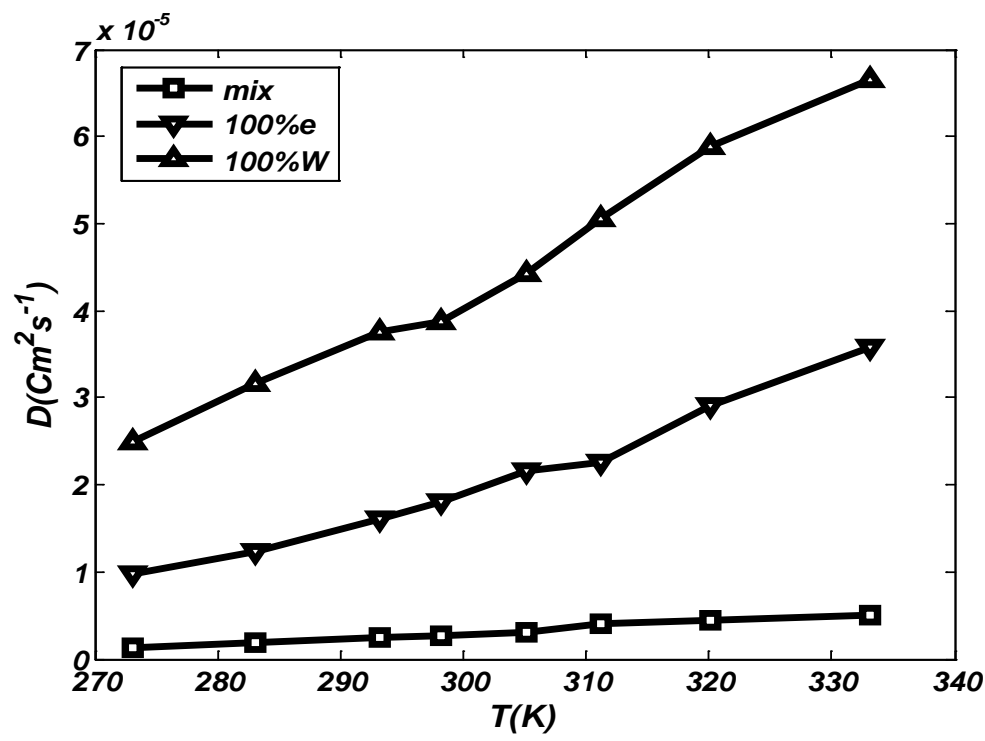

Figure 4. Self-diffusion coefficients of water/ethanol mixture, pure ethanol, and pure water as a function of temperature.

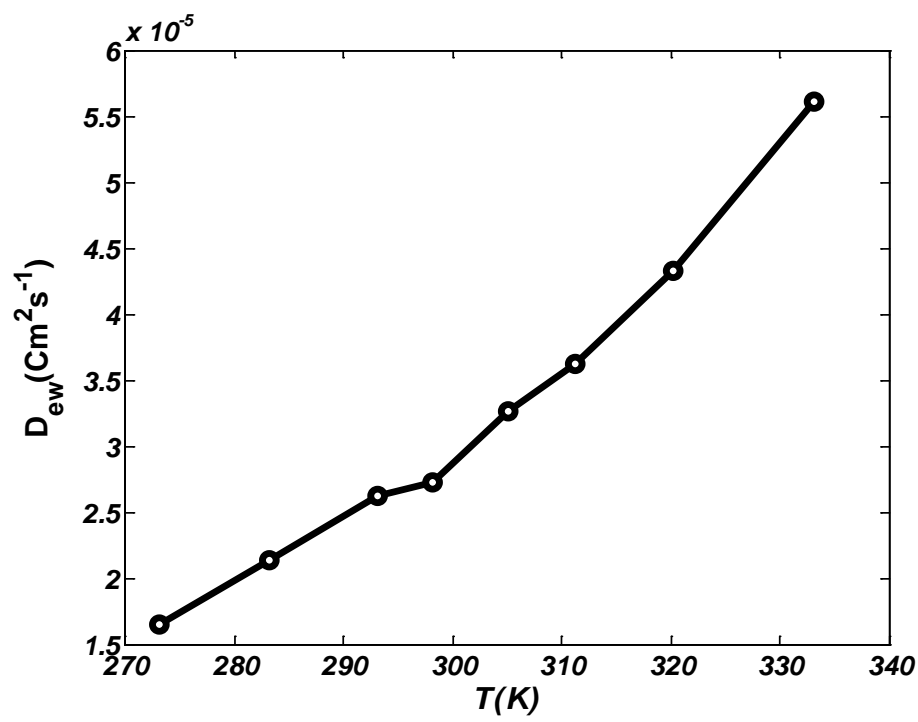

Figure 5. The mutual diffusion coefficients $\left(D_{\text {ew }}\right)$ for water-ethanol mixture ( $\left.D_{\text {ew }}\right)$ as a function of temperature. 
In Figures 6, 7, and 8 the radial distribution functions (RDF) between various atoms in ethanol-water mixture, pure ethanol, and pure water have been plotted at $\mathrm{T}=(273.15$ and 333.15$) \mathrm{K}$. These data can be used to study the local structure in the mixture

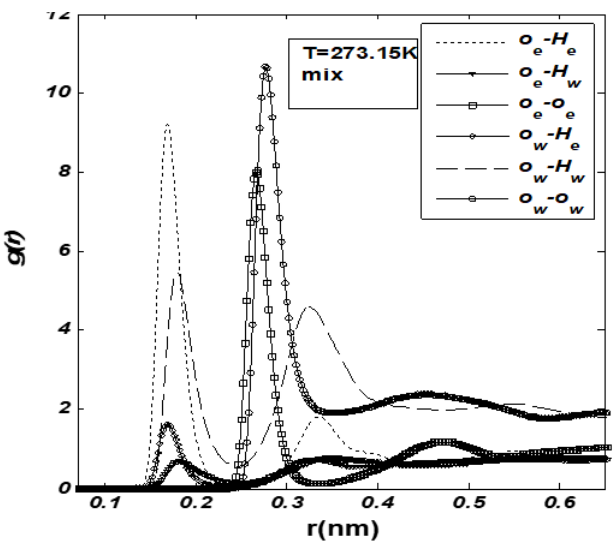

a)

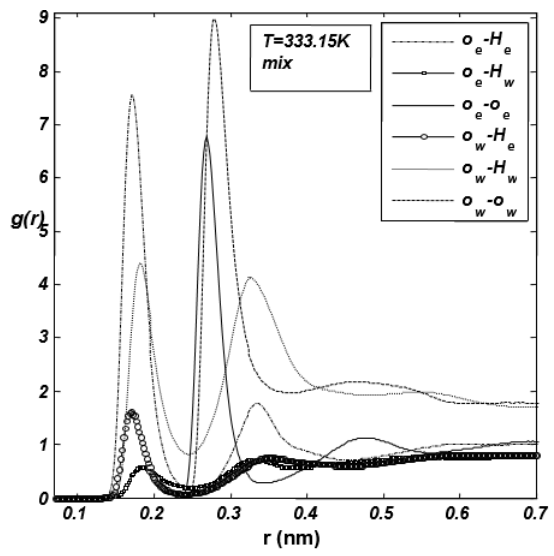

b)

Figure 6. Various partial radial distribution functions for ethanol-water mixture at

$$
\mathrm{T}=273.15 \mathrm{~K}(\mathrm{a}) \text { and } \mathrm{T}=333.15 \mathrm{~K}(\mathrm{~b}) \text {. }
$$

Figures 6, 7, and 8 show that the interaction between atoms decreases with temperature increasing. It is well known that by temperature increasing, atoms move faster and force of interactions between them decreases.

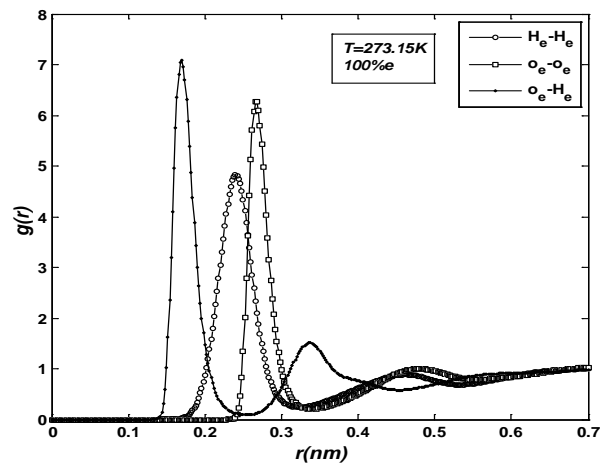

a)

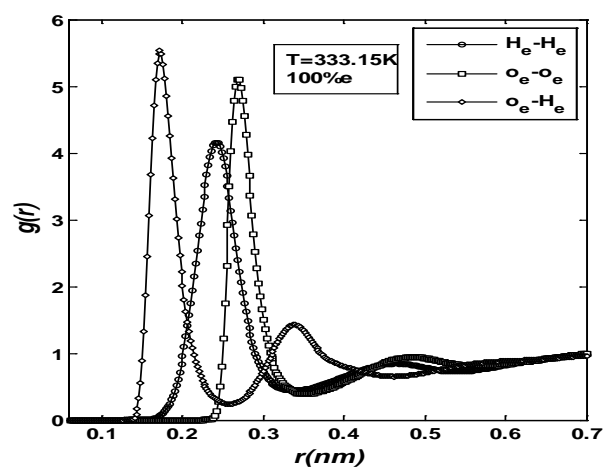

..b)

Figure 7. Various partial radial distribution functions for pure ethanol at $\mathrm{T}=273.15 \mathrm{~K}(\mathrm{a})$ and $\mathrm{T}=333.15 \mathrm{~K}(\mathrm{~b})$. 


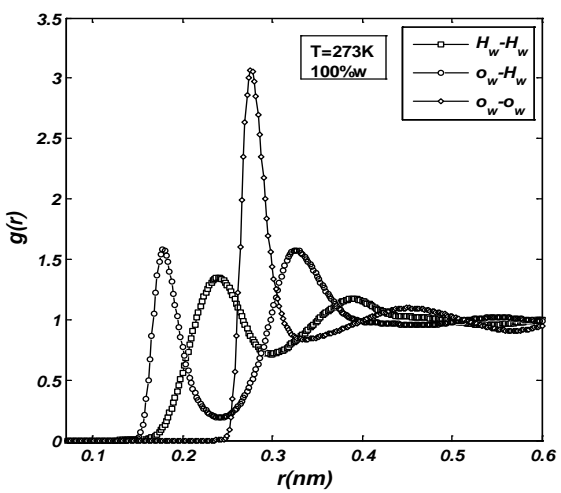

a)

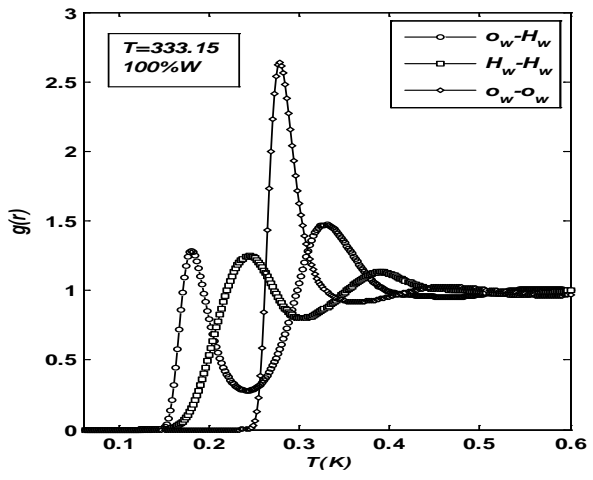

b)

Figure 8. Various partial radial distribution functions for pure water at $\mathrm{T}=273.15 \mathrm{~K}(\mathrm{a})$ and $\mathrm{T}=333.15 \mathrm{~K}(\mathrm{~b})$.

\section{CONCLUSIONS}

In this work, we calculated the thermodynamic properties (change of enthalpy, $\Delta H$, change of entropy, $\Delta S$, change of heat capacity, $\Delta C_{p}$, and change of Gibbs free energy, $\Delta \mathrm{G}$ ) for pure water, pure ethanol, water/ethanol mixture, and interaction of mixture ( $50 \%$ water $+50 \%$ ethanol) under thermal equilibrium condition at $\mathrm{T}=(273.15,283.15,293.15,298.15,305.15,311.15,320.15$, 333.15) $\mathrm{K}$ and at atmospheric pressure. This theoretical calculation was done using Molecular Dynamic (MD) simulation. Results show that the enthalpy changes and entropy changes for ethanol/water mixture, interaction of mixture ( $50 \%$ water $+50 \%$ ethanol), the pure ethanol and pure water increases by temperature growth. Also, for mixture of ethanol/water and interaction of mixture ( $50 \%$ water $+50 \%$ ethanol), the changes of specific heat decrease by temperature increasing. In addition, the value of Gibbs free energy for interaction of mixture $(50 \%$ water $+50 \%$ ethanol) at different temperatures show that this interaction can occur at $\mathrm{T}=(298.15,311.15,320.15,333.15) \mathrm{K}$.

\section{REFERENCES}

1. JC. Meyer, S. Kurasch, HJ. Park, V. Skakalova, D. Künzel, A. Groß, A. Chuvilin, G. Algara-Siller, S. Roth, T. Iwasaki, U. Starke, JH. Smet, U. Kaiser, Nature Materials, 2011, 10, 209.

2. Y. Maréchal, Journal of Molecular Structure, 2011, 1004, 146.

3. E. Yamamoto, T. Akimoto, M. Yasui, K. Yasuoka, Scientific Reports, 2014, 4, 4720. 
4. S. Le Caër, Water, 2011, 3, 235.

5. S. Jamil, S. Rauf Khan, MRS. Ashraf Janjua, Journal of the Chinese Chemical Society, 2018, 1-9.

6. H. Mevadaa, D. Patel, Procedia Engineering, 2016, 144, 110.

7. JS. Alakali, SO. Eze, MO. Ngadi, 2nd International Conference on Environment, Energy and Biotechnology IPCBEE, IACSIT Press, Singapore, 2013, 51, 149, doi:10.7763/IPCBEE.2013.V51.28.

8. T. Makarewicz, R. Kaźmierkiewicz, Journal of Chemical Information and Modeling, 2013, 53, 1229.

9. H. Dong, F. Zonta, S. Wang, K. Song, X. He, M. He, Y. Nie, S. Li, International Journal of Molecular Sciences, 2018, 19, 60.

10. Y. Zhang, Y. Ding, BMC Bioinformatics, 2016, 17, 28.

11. JA. Lemkul, WJ. Allen, DR. Bevan, Journal of Chemical Information and Modeling, 2010, 50, 2221.

12. A. Elengoe, MA. Naser, S. Hamdan, International journal of molecular Science, 2014, 15, 6797.

13. M. Lundborg, E. Lindahl, Journal of Physical Chemistry, 2015, 22, 810.

14. TT. Nguyen, MH. Viet, MS. Li, The Scientific World Journal, vol. 2014, Article ID 536084, 14 pages, 2014, doi.org/10.1155/2014/536084.

15. SMJ. Rogge, L. Vanduyfhuys, A. Ghysels, M. Waroquier, T. Verstraelen, G. Maurin, V. Van Speybroeck, Journal of Chemical Theory and Computation, 2015, 11, 5583.

16. M. Fernandez-Pendas, B. Escribano, T. Radivojevíc, E. Akhmatskaya, Journal of Molecular Modeling, 2014, 20, 2487.

17. RC. Walker, MF. Crowley, DA Case. Journal of Computational Chemistry, 2008, 29, 1019.

18. P. Johansson, A. Carlson, B. Hess, Journal of Fluid Mechanics, 2015, 781, 695.

19. PS. Krstic, L. Han, S. Irle, H, Nakai, Chemical Science, 2018, 9, 3803.

20. J. Yeow, KW. Tan, DA. Holdbrook, ZS. Chong, JK. Marzinek, PJ. Bond, SS. Chng, Journal of Biological Chemistry, 2018, ASAP, doi: 10.1074/jbc.RA118. 002441.

21. S. Toxvaerd, OJ. Heilmann, JC. Dyre, The Journal of Chemical Physics, 2012, 136, 224106.

22. MP. Gajula, A. Kumar, J. Ijaq, Protocol for Molecular Dynamics Simulations of Proteins. Bio-protocol, 2016, 6: e2051, doi: 10.21769/BioProtoc.2051.

23. D. Yu, X. Ma, Y. Tu, L. Lai, Scientific Reports, 2015, 5, Article number: 8640.

24. F. Vitalini, F. Noé, BG. Keller, Data in Brief, 2016, 7, 582.

25. D. van der Spoel, AR. van Buuren, MEF. Apol, PJ. Meulenhoff, DP. Tieleman, ALTM. Sijbers, B. Hess, KA. Feenstra, E. Lindahl, R. van Drunen, HJC. Berendsen, GROMACS User Manual version 3.3, Department of Biophysical Chemistry, University of Groningen, The Netherlands, 2001.

26. F. Koohyar, AA. Rostami, MJ. Chaichi, F. Kiani, Journal of Solution Chemistry, 2011, 40, 1361. 